INTERNATIONAL JOURNAL OF MULTidisciplinARY RESEARCH AND ANALYSis

ISSN(print): 2643-9840, ISSN(online): 2643-9875

Volume 04 Issue 01 January 2021

DOI: 10.47191/ijmra/v4-i1-09, Impact Factor: 5.522

Page No.- 58-63

\title{
Promoting the Development of Creative Management in Uzbekistan
}

\author{
M.B. Yuldasheva \\ Associate Professor, Department of "Organization and management of institutions of culture and art", \\ Tashkent, Uzbekistan
}

ABSTRACT: This article argues that the creative department should be fully focused on the full disclosure of the creative potential of the people of the Republic of Uzbekistan. The goal of creative management is to generate new ideas and find new solutions for the success of the country, company and organization in various fields.

KEYWORDS: Creativity, creative management, creative entrepreneurship, culture, art, culture.

\section{INTRODUCTION}

By creative management we mean the effective management of structures, processes and resources to achieve set goals using non-standard (creative) approaches. The concept of creative management intersects with the concept of innovation management (from the word "innovate" - to introduce innovation, to make changes), but is not limited to it. The relationship between innovation and creativity in a simplified sense is given by the definition: "Innovation is the borrowing, adaptation or practical use of a creative element." At the same time, innovation, that is, innovation in the economy, technology, service, can also have a creative component, contain elements of creativity.

The need for creative management arises when standard principles and methods of management fail; namely: a issue and conflicting management requirements; incomplete certainty and variability of the environment in which management is carried out; insufficient control mechanisms to compensate for disturbances (failure to comply with the principle of diversity); active opposition from competitors and the external environment in general, as well as other circumstances that do not allow to ensure effective management of known tools.

Creative management is characterized by: 1) the search for alternative strategies in the expanded space of feasible solutions - already here, in the expansion of the space, creativity manifests itself; 2) analysis of alternatives using multi-criteria optimization - creativity is manifested in the choice of quality criterion and optimization methods; 3 ) creation of a mechanism for implementing strategies taking into account the human factor - here creativity is manifested in finding an economical mechanism and creating conditions for the full use of the intellectual potential of personnel; 4) ensuring effective control over the implementation of the plan - in this task, creativity should help to find a compromise between the cost of the control system and its guaranteed effectiveness.

Recently, the terms "creative entrepreneurship" and "creative management" are increasingly used. Entrepreneurship and startups are a buzzword today. They write about them, talk about them discusses them. The development of your business is a kind of trend that you need to follow. However, not everyone succeeds. Perhaps the point is that aspiring businessmen cannot correctly identify the area in which they would like to develop. More recently, a new trend has emerged in the world - creative entrepreneurship. Perhaps this is exactly the innovation that will help find innovative approaches to business.

In Uzbekistan, it was customary to call workers of literature and art as creative workers. In fact, a person of any profession creates, if he finds a new solution to a known problem solves a problem or opens a new direction. The very process of creativity begins with the search for ideas. The basis of this search is - problems, goals, objectives of the organization.

Currently, in Uzbekistan there is an increasingly active penetration of creativity from the sphere of art and science into other spheres of human activity. The sphere of management was no exception. In management theory, more and more attention has recently begun to be paid to the problem of widespread use of the creative potential of managers and top managers of an enterprise [9. - p. 47]. In many institutes and universities, special courses in creative management appear which contribute to the development of skills for innovative creative solutions in management and business. Numerous courses and trainings have also found wide application, which contribute to the improvement of creativity and help to learn how to find creative ideas. Significant 


\section{Promoting the Development of Creative Management in Uzbekistan}

changes in technology and competition simply force companies to develop unconventional approaches to solving traditional problems, to look for fundamentally new solutions.

Thus, within the framework of the British Council's art program in Uzbekistan, partnerships are being established with leading British universities in the field of creative economics and creative entrepreneurship. From January to February 2018, Gerald Lidston, Director of the Institute for Creative and Cultural Entrepreneurship in Goldsmiths, and Steve Conway, Dean of the University of Leicester, visited Uzbekistan. The topic for discussion by the British Council in Uzbekistan was chosen as very important in all respects - discussion of cooperation in the field of creative entrepreneurship.

\section{THE MAIN FINDINGS AND RESULTS}

During the visit, meetings were held with the leadership of the Ministry of Culture of Uzbekistan, the Fund for the Development of Arts and Culture under the Ministry and the Institute of Arts and Culture. Guests from the UK, leading experts in this area in the UK Gerald Liston and Steve Conway also held consultations and seminars for the main group of teachers and trainers in art and economics in Uzbekistan in order to study the international experience of teaching creative entrepreneurship and prepare new programs for higher education.

The seminar, held at the International Business Center of Tashkent, was aimed at:

- Discussion of the basic principles and components of the creative economy and creative entrepreneurship;

- Discussion of the main components of teaching creative entrepreneurship in the UK and the priorities in this area in Uzbekistan;

- Discussion of examples of successful projects in the field of creative entrepreneurship from the UK and other countries in order to consider approaches to the project for the development of creative entrepreneurship skills, in the framework of the British Council's partnership with the Ministry of Culture of the Republic of Uzbekistan, the Fund for the Development of Culture and Arts and the Institute of Arts and Culture under the Ministry.

The British Council announced the launch of the Creative Spark program, a five-year initiative to support international universities and create international partnerships to develop entrepreneurial skills and the creative economy in seven countries, including Uzbekistan.

The program includes developing partnerships between universities and creative institutions in the United Kingdom and countries participating in the program to support entrepreneurial skills training and create entrepreneurship centers.

Her other focus is on the development of entrepreneurship curricula for students and creative entrepreneurs, which will include topics such as pitching ideas, starting a business, protecting intellectual property and obtaining loans.

The third area of the program is teaching English by providing access to educational digital resources, including learning platforms, online courses and massive open distance learning courses with an emphasis on English for entrepreneurs.

The organizers expect that the applications will focus on developing the skills of students and young creative entrepreneurs, supporting new business initiatives and incubators, and sharing knowledge. The State Institute of Arts and Culture of Uzbekistan also applied for participation in the Creative Spark program.

In modern management, the management of the processes of the formation of new ideas is now referred to as "creative management". One of the characteristics of creativity (creativity) is intelligence. As a complex mechanism, intelligence includes creativity as its own part, i.e. creativity is the natural mechanism of the brain when solving emerging problems, and creative management is designed not only to manage science-intensive industries and creative teams, but also to show art, to make the only correct decision in unforeseen situations [2. -p. 79].

Therefore, the purpose of this article is to study the implementation, use and development of creative thinking in the work of a manager, as well as a system for managing the process of making creative decisions by creative employees, teams, etc.

The beginning of the introduction of a creative approach into management activity happened relatively recently, but this process was characterized by a very rapid pace of development. Creativity has become an integral part of management. As a result, a type of management has emerged that is responsible for managing the creative process - the so-called "creative management". First, it is necessary to clarify how the concepts of "creativity", "creative thinking" and "creativity" are related.

Creativity is an activity, the result of which is the creation of new material and spiritual values. Creative thinking is the ability to generate unusual and innovative ideas, find fundamentally new, unique solutions, create a new look at things connect objects or images in a way that has not been connected before.

Creativity (or divergent abilities) - the ability to generate many different original ideas regarding the same object. Creativity criteria:

1. Fluency - the number of ideas generated per unit of time

2. Originality - the ability to generate "unique" ideas 


\section{Promoting the Development of Creative Management in Uzbekistan}

3. Susceptibility - sensitivity to unusual details and contradictions

4. Metaphoricity - the willingness to work in a fantastic, "impossible" context, the tendency to use symbolic, associative means to express thoughts.

Creativity (from Lat. Creatio - creation, creation) - creative, constructive, innovative activity,

Creatira (from Lat. Creatira - creation, creation) - a) creation; b) henchman of an influential person, obedient executor of the will of his patron, for example: man is the creation of God (creator).

Manager - a specialist professionally engaged in management activities in a specific area of the functioning of the economic system (institutions, organizations, enterprises, firms, etc.).

Management - activities to streamline the processes occurring in society, nature, technology, eliminate their disorganization, reduce uncertainty and bring them into a necessary state, taking into account the trend of their development and changes in the environment.

Management is a special form of management activity. Various types of functional management are involved in the management of various fields of activity. The beginning of the sphere of innovative activity is the creative activity of a person to create an intellectual product from idea to innovation - this area of activity is what creative management deals with.

Creative management is a method of managing the creative process focused on solving urgent collective problems. Creative management is based on modern technologies of creativity and teamwork [3. -p. 57].

The task of creative management is to manage the process of making creative decisions in a team. The currently extremely popular methodology shows effectiveness where other systemic strategies cannot "cope" and is a very relevant way to combine conservative logical thinking with the laws of modern management and the flight of creative imagination.

Intellectual capital is knowledge, information, experience, organizational capabilities and information channels, that is, everything that can be used to create capital (wealth) accumulation. In other words, it is the sum of all knowledge, experience, connections owned by a person, organization, corporation, country, which forms their competitiveness.

Creative management must ensure the minimum costs of creating the foundation of intellectual capital and the maximum potential income in the future. The main application of creative management is the creation and motivation of human capital, the activation of its creative potential.

The goals of creative management:

1. Give person knowledge

2. Provide him with information

3. Encourage a person to be creative

4. Ensure his rights to the results of his creative (intellectual) work

5. To ensure the rights and interests of the organization (economic system), which provided a person with knowledge, information, conditions for creative activity, legal protection of the results of creative work.

Human capital is a part of intellectual capital that is directly related to a person (knowledge, practical skills, creative and mental abilities of people, their moral values and their work culture). This capital is the property of a person. When intellectual capital becomes the property of an organization, it passes from the category of human capital to the category of consumer capital, and this is already a commodity that is an object of purchase and sale. Part of the human capital always remains with a person and moves with him (knowledge, experience, skills, creativity, image, morality, culture, etc.).

A person makes physical and other expenses constantly during his life to create his intellectual capital, and to perform physical work only at the time of its execution. Intellectual capital, like physical capabilities, a person always has with him and can turn it into a commodity, and a commodity into money, compensating for the costs of past periods.

The task of the organization (management) is to create attractive conditions for human capital and exclude its migration. The task of creative management is to ensure active, effective, creative (intellectual) human activity (human capital) [11, -p. 78].

M. Tring: "the creative essence of an invention is a new constructive principle that cannot be derived from known ideas by logical inference" [7. -p. 91]. Such innovations should have the following characteristics [16. -p. 84]:

1. Creative power - high novelty and usefulness.

2. Strategy - to provide competitive advantages and successful corporate activities in the market in the long term.

3. Implementation - to be implemented in the form of specific processes, goods and services.

4. Profitability - to maximize the value of the final product for consumers, the enterprise and society.

In modern management, the management of the formation of such new ideas is currently referred to as "creative management", which is part of innovation management. Creative management is implemented at the pre-project and design 


\section{Promoting the Development of Creative Management in Uzbekistan}

stages of the innovation cycle, the task of which is to form and select new ideas for their practical implementation in innovative projects.

Creative management should be aimed at the full disclosure of the creative abilities of people [6. -p. 97]. Whereas traditional administration is based on the implementation by people of firmly established rules and is not aimed at showing them initiative and revealing all their abilities,

Creative management refers to the management of people in organizations, aimed at maximum disclosure and use of their creative abilities at the pre-project and project stages of the innovation cycle to create new, competitive ideas at the level of inventions in various fields of human activity.

The purpose of creative management is to generate new ideas and search for new solutions to achieve the success of a country, company and organization in various fields. At the same time, people management is carried out both in the organization itself (personnel) and outside it (suppliers, partners, intermediaries, clients, consumers and other target audiences).

Creative translated from English means creative, constructive. According to Webster's Dictionary, "creativity is the ability to create new meaningful forms." In a broader sense, creativity is the process of revealing hidden opportunities and creative use of their potential in a certain area [17, -p. 72].

Creativity is not identical with intelligence, which is understood as the ability to analyze and process and assimilate large amounts of information. It assumes the ability to synthesize and create new.

The result of creative synthesis can be inventions, new theories, understanding of the problem works of art. Creativity is the main prerequisite for creating innovation. New (creative) ideas, which are usually obtained through creative thinking or by borrowing, become innovations. Creativity has always been the main source of the development of society.

Creativity in society depends on the historical situation. If in antiquity and the Middle Ages creativity was manifested mainly in art, then, starting from the second half of the 17th century and until the first half of the 19th century, it manifested itself mainly in science and art. From the second half of the XIX century - in science and technology, and from the middle of the XX century, it manifests itself primarily in technology and economics.

Currently, creativity in developed countries is becoming a constant practice and the main source of competitive advantage. In almost any area of production, the creativity wins in the end.

Creativity has the following main forms:

- Scientific (discoveries)

- Technical (inventions)

- Economic (entrepreneurship)

- Artistic (art)

- Social (relationships with people)

- Political (public administration)

The term "creativity" comes from the Latin word "creatura", which means creation, creation. It is no coincidence that when speaking of human creativity, first of all, we mean a creative person who thinks outside the box and in an original way. This concept also includes such qualities as flexibility, learning, independence, the desire to find a way out of the most desperate situations, etc.

Creativity is becoming more and more important not only for creative professionals, but also for managers. It's all about the fast pace and versatility of modern life, which require the ability to flexibly and creatively respond to ongoing changes. No company today can afford to relax: the competition is extremely fierce. That is why employers are so interested in people who are able to think outside the box, find new ideas and approaches to management. Candidate requirements for a wide variety of roles - from office executives to sales managers - increasingly feature creativity and creative thinking. Creativity before our eyes is becoming an increasingly demanded quality in the labor market.

Initially, the creativity of managers was associated with the sphere of their professional activity. For example, it was believed that managers of private firms were more creative than managers of large state-owned enterprises, and advertisers were more creative than financiers. However, studies carried out by Western experts have proven that there is no connection between creativity and the field of activity of a specialist. Creativity is an internal quality of a person, depending on his personal characteristics. After all, financiers often introduce innovations that optimize employee performance.

What makes a creative manager different? First of all, the lack of fear of stereotypes, he boldly destroys long-standing traditions and introduces innovative solutions. This approach to day-to-day operations allows the company not only to stay afloat, but also to bypass its competitors. After all, a creative manager understands that any technology, new product or type of service lags behind life very quickly. Therefore, he does not fight against changes, but foresees them, making non-standard decisions and thereby bringing the company to the forefront. 


\section{Promoting the Development of Creative Management in Uzbekistan}

When hiring a new manager, the employer evaluates not only the business qualities and professional experience listed in the resume, but also personal characteristics. For this, the candidate is invited for an interview. It is quite simple to check the creativity of a specialist in the creative profession: just look at his portfolio. This applies to advertising managers, designers, journalists, etc. But what about financiers, sales managers and other professionals, it would seem, far from creativity? In fact, it's not difficult either. You should offer the candidate as a test task any situation typical for a particular company that requires a prompt solution. If the manager acts according to the standard scheme adopted in the given firm, it is already good. This means he is a tough professional. If he offers an unexpected scheme of actions, which, moreover, allows us to resolve the situation as quickly as possible or at the lowest cost, then we have a creative professional.

It follows from the above that creativity should be based on solid knowledge and professional experience, to which a flexible mind and creative thinking are attached. Looking at the problem from different points of view, a creative manager will be able to offer a non-standard solution. In addition, creative people, as a rule, are extremely charismatic, which means they can captivate the team with their ideas, which is also very important for a manager.

Creativity, like any quality of character, can be developed and stimulated. Each of us has potential abilities that can be revealed with a competent approach. What is needed for this?

A favorable psychological climate in the team is very important. A person can work creatively only where he feels good. To do this, he needs as much freedom and independence as possible. It is necessary to maximally use the knowledge and skills of employees, provide them with the opportunity for self-realization. It is especially important to minimize stressful situations, prevent them or quickly resolve the problem. We must not forget about personnel training. For the development of creativity, new information is constantly needed, which can be obtained at conferences, trainings and seminars. Good suggestions and ideas should definitely be encouraged. And one should not be afraid of praise - for creative people, the assessment of their work is very important. Sometimes even more important than material incentives, the above applies not only to potentially creative employees, but also to those managers whose non-standard thinking is beyond doubt. The employer must clearly understand that the creativity of the employees helps the company to remain competitive in many ways. This means that this quality must be developed and cultivated in every possible way [14. - p. 85].

In connection with the conditions of tough competition in the modern market for goods and services, employers of many companies are interested in people who are able to think outside the box, find new ideas and approaches to management. The level of our creativity is not determined by hereditary factors, but is formed under the influence of the environment moreover it can change in one direction or the other during life. Downturns in creativity are mainly associated with either a decrease in its relevance, or with stressful situations. That is why the development and stimulation of creativity becomes relevant. Many different methods have been created for this. The creative process is an integral part of a manager's activity. But in parallel with the development and stimulation of the manifestation of creativity, there are blocking factors. So, for example, an unfavorable environment in the team can negatively affect the results of the creative activity of the staff. To do this, managers need to monitor the fulfillment of certain conditions that oppose the suppression of the manifestation of creativity. The result will be a wellcoordinated team and huge creativity.

The main difficulty in generating new ideas that help solve problems and tasks is moving away from the usual ways of associating information. This "logic of experience" prevents us from combining information in unusual ways. We find it difficult to see ordinary situations in a new light. The linking of incomparable pieces of information can be deliberately excluded, and ideas that seem irrelevant may not "come up" from memory due to their weak connection with the situation. As a result, we fail to explore all possible solutions to the problem. There are many different methods to help you generate new ideas. The emphasis is more on the quantity of ideas created than on their quality. This provides many ideas that can be applied to formulate decisions that are subsequently evaluated. For example, in product policy, the search for ideas is the constant, systematic search for opportunities to create new products, including identifying sources of new ideas and methods of creating them.

An important element in almost all of these methods is the deferral of the assessment, which means deliberately avoiding any type of assessment. Evaluating ideas inhibits the imagination and prevents the mind from making atypical and potentially useful connections. Sometimes it can be easy to come up with unusual or radical ideas, for example, when we know that we are only "playing". However, as soon as we are faced with a serious task, we immediately exclude these ideas, consciously or unconsciously, simply because they are usually not associated with a practical solution or are too risky.

The main sources of ideas include: consumers (information comes from surveys, observation and experiment, as well as complaints), research laboratories, individual scientists and experts, competitors, sales personnel, advertising agencies, operating and service organizations, members of groups using creative methods generating ideas.

The task of creative management is the formation of new competitive ideas and the search for effective solutions at the pre-project and design stages of the innovation cycle for their implementation in innovative projects at different levels of the 


\section{Promoting the Development of Creative Management in Uzbekistan}

economy and society, aimed at achieving the success of an enterprise, organization, firm, industry, region or country as a whole various fields of activity.

At the pre-project stage, the search and generation of new ideas, their assessment and selection are carried out. At the design stage, the development of selected ideas is carried out at the stages of fundamental and applied research and experimental design development. To solve these problems, special methods of generating new ideas are used.

Creative management involves the implementation of the following functions:

1) Analysis and forecasting of the development of the object and the external environment;

2) Statement of problems and tasks;

3) Collection and analysis of information necessary for their solution;

4) Application of special methods and techniques to generate new ideas and make effective decisions;

5) The formation of new ideas and the development of alternatives for solving problems and tasks;

6) Assessment of alternatives according to different criteria;

7) Choosing the best alternative for solving problems and tasks.

8) Elaboration of the concept and plan for solving the problem and tasks;

9) Leadership based on collaboration;

10) Motivation of personnel for cooperation and innovation;

11) Continuous development of personnel;

12) Development of the intellectual potential of the organization.

\section{CONCLUSION}

Creative management is aimed at solving problems and tasks of innovative development based on systems analysis, network, collective thinking and the use of special creative methods of developing innovations. These methods are aimed at generating new ideas among specialists and are widely used in practice in various fields of economics and technology. Creative (creative) methods form a fund of search procedures and heuristic methods for finding new technical solutions.

Against the background of the above, a reasonable question arises: how does creative entrepreneurship differ from the usual business, why did you need to introduce new concepts? The point is that creative entrepreneurship is fundamentally different from the usual work norms it requires great skills, mobility and the ability to constantly learn. Without this, it is simply not possible to stay "on the wave". "Creative manufacturing is the factories of the future. Most creative companies are small or even micro businesses, very mobile, often seasonal, project-based. They are very different from the old 8 to 17 production model, where people spend most of the time. Your life Creative entrepreneurship requires a variety of skills and the use of a variety of working methods. And the most difficult thing is that, at the moment, no good models have been developed to assess the real value of intellectual capital - the basis of creative entrepreneurship. This greatly complicates the search for investors and financing", - explains Ragnar Siil. The expediency of using one method or another depends on the complexity of the problem being solved, while different methods can be applied at different stages of innovative projects.

\section{REFERENCES}

1. Alshuller G.S., Shapiro R. B "On the psychology of inventive creativity, Questions of psychology" / N6, 1996

2. Beletsky N.P. "Intellectual technique of the manager: Textbook. manual "/ New knowledge, 2001.

3. Wikipedia is an electronic encyclopedia. http://ru.wikipedia.org

4. Vanyurikhin G.I. "Creative management" / Management in Russia and abroad. N 2, 2001

5. Vanyurikhin G.I. "Creativity in Management" / Bulletin of the International University. Series "Management", 2000

6. Danton E. "Innovation: how to identify trends and benefit" / M., 2006

7. Kandaurov N.N., et al. "Innovation management" / Modern knowledge, 2006

8. Kirsanov K. "Creative and heuristic management" 3/5/2004 http://www.ovsem.com

9. Kirsanov K. "Creative and heuristic management", G. Vanyurikhin "Creative management" / Management in Russia and abroad. N 2, 2001

10. "Creative thinking in business"/ Alpina business Books, 2006

11. McConnell C.R., Bruce S.L. Economics. INFRA-M. 2003

12. "Psycho-gymnastics in training" Ed. N.Yu. Cartilaginous. / SPb : Speech, Training Institute, 2002

13. Simonov P.V., Romanovskaya T.B., Fainberg E.L. "Questions of Philosophy" / N 1, 1994

14. Article. Lyubov Tsoi, Art. n. Researcher, Institute of Sociology, Russian Academy of Sciences, Cand. social Sciences, Ch. corr. RANS scientific consultant of the project "Conflict management in management consulting"

15. Article. Stanley Sommersby "7 Commandments of the Creative Manager" / July 2007

16. Tring M., Leithwaite E. "How to Invent?" / World, 1980

17. Florida R. "Creative class: people who change the future" / M., 2005 